\title{
Motivos da escolha do automóvel no acesso a megaeventos: caso da Copa das Confederações 2013, Rio de Janeiro
}

\author{
Reasons to choose private cars to attend megaevents: \\ case of the 2013 Confederations Cup, Rio de Janeiro
}

Nathaly Escobar ${ }^{[a]}$, Josefina Flórez ${ }^{[b]}$, Licinio da Silva Portugal[a]

[a] Universidade Federal do Rio de Janeiro (UFRJ), Instituto Alberto Luiz Coimbra de Pós-graduação e Pesquisa em Engenharia (COPPE), Programa de Engenharia de Transportes (PET), Rio de Janeiro, RJ, Brasil

[b] Universidad Simón Bolívar (USB), Departamento de Planificación Urbana, Caracas, Miranda, Venezuela

\section{Resumo}

Realizar um megaevento implica em inúmeros e significativos impactos, em especial na mobilidade urbana, cujo tratamento e mitigação exigem adequadas estratégias e políticas, dentre as quais se destaca o incentivo ao uso dos modos de transporte mais sustentáveis. A efetividade das estratégias dependerá de diversos fatores que interferem no processo de escolha modal. Neste artigo, com base em consulta a mais de mil espectadores que assistiram aos jogos da Copa das Confederações 2013, realizados no Rio de Janeiro, pretende-se apresentar e analisar os principais motivos que influenciaram no uso do automóvel. Adicionalmente, a partir de uma revisão bibliográfica, identificam-se os motivos instrumentais que incidem na escolha do automóvel, confrontando-os com os obtidos na nossa pesquisa. Mesmo que tais motivos e sua hierarquização sejam suscetíveis a mudar no tempo e sensíveis às especificidades locais, parece que, no caso das cidades brasileiras, sistemas de transportes alternativos ao automóvel apresentam uma forte deficiência quanto a atributos como o conforto e a rapidez, o que ressalta a necessidade de não só restringir o acesso ao automóvel, mas de se investir na melhoria dos transportes públicos e não motorizados, tornando-os opções mais atraentes para os usuários de automóvel realizarem a transferência modal.

Palavras-chave: Uso do automóvel. Escolha modal. Fatores intervenientes na escolha modal. Megaevento esportivo. Rio de Janeiro.

\section{Abstract}

Mega events involve numerous and significant urban impacts, especially regarding urban traffic, which treatment and mitigation require appropriate strategies and policies. The promotion of more sustainable modes of transportation is one of the most important. The strategies effectiveness will depend on several factors that

NE é urbanista; Especialista - MBA em Marketing, e-mail: escobar.nathaly@gmail.com

JF é urbanista; Doutora Engenheira de Caminhos, Canais e Portos, e-mail: jflorez@usb.ve

LSP é engenheiro civil; D.Sc - Doutor em Ciências - Engenharia de Produção, e-mail: licinio@pet.coppe.ufrj.br 
affect the modal choice process. In this article, based on consultation with more than a thousand spectators who attended 2013 Confederations Cup held in Rio de Janeiro, we intend to present and analyze the main motivators for the use of car in this mega event. Additionally, instrumental motives that affect car choice were identified based on a literature review, facing that with those obtained in the field. Even when the modal choice motives and their hierarchy are susceptible to change over time and depends on local context, it seems that in the case of Brazilian cities, systems of transportation other than cars strongly lack in attributes such as comfort and speed. What highlights the need not only to restrict access of individual transport, but also to invest in the improvement of public and non-motorized transportation, making them more attractive options for car users.

Keywords: Car use. Modal choice. Factors influencing modal choice. Sport mega-event. Rio de Janeiro.

\section{Introdução}

Estratégias vêm sendo implementadas em todo o mundo com vistas a se reduzir o uso do automóvel, fruto dos seus potenciais impactos econômicos, ambientais e sociais com repercussão na qualidade de vida da população (Redman et al., 2013; Rodrigues et al., 2013). 0 sucesso delas depende do conhecimento dos motivos e dos fatores que interferem na escolha dessa modalidade individual, o que pode justificar as diferentes pesquisas realizadas com esse propósito, feitas especialmente em países desenvolvidos (De Witte et al., 2013; Tyrinopoulos \& Antoniou, 2012).

Tais estratégias se replicam em megaeventos, o que se reforça pela alta concentração de viagens no tempo e no espaço, além do possível incremento da demanda de viagens pela presença de turistas. Isso explicita a necessidade de não só restringir o acesso de automóveis no local, mas também priorizar os modos mais produtivos socialmente, como o não motorizado e o coletivo, em especial os de maior capacidade (Malhado, 2012; Robbins et al., 2007).

No entanto, nos últimos anos, megaeventos de naturezas distintas estão sendo realizados em países em desenvolvimento (Copa do Mundo 2010 na África do Sul, Jogos da Commonwealth 2010 na Índia, Jornada Mundial da Juventude 2013 no Brasil, Copa do Mundo 2014 no Brasil, Jogos Olímpicos e Paraolímpicos 2016 no Brasil, Jogos Olímpicos da Juventude 2018 na Argentina), tipicamente caracterizados por sistemas de transportes deficientes, desarticulados entre si e não integrados ao desenvolvimento urbano (Portugal et al., 2010). Países onde também se verificam políticas de incentivo à aquisição de veículo particular, somadas à postura cultural histórica que posiciona a disponibilidade ou a posse do automóvel como símbolo de status, liberdade e mobilidade absoluta (Ramis \& Santos, 2012).

Determinar os motivos de escolha de um modo de transporte pressupõe conhecer as razões pelas quais as pessoas preferem uma modalidade do que a outra. Normalmente, quando um usuário é questionado sobre os motivos de sua preferência modal, ele justifica sua escolha por meio das vantagens e desvantagens dos modos disponíveis, percebidas direta ou indiretamente (Abrahamse et al., 2009; Anable \& Gatersleben, 2005; Beirão \& Cabral, 2007; Eriksson et al., 2013; Gardner \& Abraham, 2007; Gatersleben, 2007; Bergstad et al., 2011; Lavery et al., 2013; Steg et al., 2001), motivos estes que se classificam na literatura como instrumentais (Eriksson et al., 2013; Bergstad etal., 2011; Lavery et al., 2013).

No caso específico do automóvel, há um outro conjunto de motivos denominado simbólico-afetivo, ou não instrumental, relacionado às razões psicológicas evocadas com o uso desse modo e que estão conectadas ao lado afetivo (sensação de liberdade, desfrute ou estresse por seu uso) e simbólico (poder, status, controle) (Anable \& Gatersleben, 2005; De Witte et al., 2013; Haustein et al., 2009; Schwanen et al., 2012; Steg, 2005). Porém eles são mais bem elucidados quando aplicados métodos qualitativos, como as entrevistas em profundidade (De Witte et al., 2013; Gatersleben, 2007; Steg et al., 2001; Steg, 2005).

Conhecer os motivos pelos quais as pessoas escolhem o modo de transporte durante um megaevento parece não ter sido objeto de pesquisa dentre a bibliografia consultada, provavelmente pela perecibilidade dos eventos. Entretanto, estes podem representar oportunidades para o teste de políticas e estratégias que estimulem ou reforcem comportamentos de viagem, abrindo espaço para padrões de mobilidade 
alternativos mais condizentes com a sustentabilidade e que poderiam ser replicados diariamente.

Este artigo tem como objetivo apresentar e caracterizar os motivos - fundamentalmente de caráter instrumental - pelos quais os espectadores escolheram o automóvel para ir aos jogos realizados no estádio do Maracanã, localizado no Rio de Janeiro, Brasil, durante a Copa das Confederações 2013 (CC2013), com base em consulta envolvendo mais de mil participantes desse megaevento.

A fim de medir a influência das estratégias implementadas durante o megaevento, principalmente as de restrições de acesso ao automóvel, avalia-se ainda a possibilidade de mudança de modalidade a partir da experiência realizada no megaevento e como a experiência cotidiana no uso do transporte público (TP) afeta no processo de escolha modal.

Com base em uma revisão bibliográfica, a primeira parte deste artigo explica os motivos instrumentais, seu papel na escolha do automóvel e sua inter-relação com fatores espaciais, socioeconômicos e a experiência de viagem. Posteriormente, descrevem-se as características da pesquisa quanto à amostra e condições em que foram aplicados os questionários. A seguir, apresentam-se os resultados obtidos na pesquisa, assim como as relações com os observados na revisão bibliográfica. E, por último, aparecem as conclusões e contribuições desta pesquisa.

\section{Motivos de escolha do automóvel e a relação com as experiências de viagem}

A preferência de um modo de transporte sobre outro pode ser determinada por diversos fatores, como os socioeconômicos, os espaciais, os da própria viagem, as modalidades disponíveis, os atributos da qualidade da viagem e a experiência em realizá-la (Anable, 2005; Anable \& Gatersleben, 2005; Gardner \& Abraham, 2007; Haustein et al., 2009; Lavery et al., 2013; Ortúzar \& Willumsen, 2011; OECD, 2011; Steg, 2005; Verplanken et al., 1994, 1997).

Segmentos com nível de renda alto tendem a mostrar uma relação positiva de uso do automóvel, em especial quando existem restrições de acesso a outros modos de transporte e quando há estacionamento no local de origem e destino (De Witte et al., 2013). Igualmente, longas distâncias tendem a incentivar o uso dessa modalidade, especialmente quando os deslocamentos a pé ou por bicicleta não se justificam e não existe um TP adequado para percorrê-las (Schwanen \& Lucas, 2011).

As modalidades disponíveis compreendem as facilidades de transporte que o indivíduo possa usar e conheça desde o início até o final da viagem. Nesse sentido, as pessoas também avaliarão quais atributos da qualidade desses modos são mais atraentes ou importantes na viagem. A percepção do indivíduo com relação a esses atributos ou a experiências de viagens anteriores poderá igualmente influenciar no processo de escolha modal. Atributos e experiências positivas reforçarão a preferência de modalidades em futuras escolhas e o comportamento do usuário, inclusive até pontos em que o raciocínio acaba sendo dispensado pelo hábito de uso da modalidade (De Witte et al., 2013; Haustein et al., 2009; Verplanken et al., 1994, 1997).

Pesquisas têm mostrado que os usuários de automóvel avaliam mais favoravelmente a experiência de viagem em comparação a usuários de outros meios de transporte (Anable \& Gatersleben, 2005; Beirão \& Cabral, 2007; Gardner \& Abraham, 2007).

Apesar da importância desse conjunto de fatores que pode afetar o processo de escolha modal, as pessoas estão propensas a expressar os motivos que incentivam sua viagem por meio das vantagens que lhes são mais perceptíveis, normalmente associadas aos atributos da qualidade da viagem (como rapidez, conforto, segurança, conveniência, flexibilidade e acessibilidade) e outros mais relacionados às suas externalidades (o custo, a proteção ao clima, os benefícios à saúde) (Gatersleben, 2007). A Tabela 1 apresenta, a partir de uma revisão bibliográfica, a classificação e a definição dos motivos instrumentais associados à escolha do automóvel.

Pretendendo dispor-se de uma visão mais abrangente sobre os motivos pelos quais as pessoas escolhem o automóvel, foram consultadas 12 pesquisas sobre esse tema, extraindo-se os principais motivos pelos quais o usuário justificou a sua escolha modal e classificando-os, como mostra a Figura 1, de acordo com a frequência de citações.

Comparando os resultados das pesquisas consultadas, observou-se que não existe consenso sobre os principais motivos que incentivam o uso do automóvel, inclusive quando se aplicam a propósitos específicos (trabalho, educação, lazer etc.), ressaltando a rapidez e o conforto como os mais citados. A segurança parece ser um atributo mais valorizado pelas mulheres, as 
Tabela 1 - Classificaçã̃o e definiç,ão dos motivos instrumentais relacionados à escolha do automóvel

\begin{tabular}{|c|c|c|}
\hline \multirow{7}{*}{$\begin{array}{l}\text { Atributos da } \\
\text { qualidade } \\
\text { da viagem }\end{array}$} & Conforto & $\begin{array}{l}\text { Condicōes proporcionadas na } \\
\text { nivel de rứdo aceitável, taxa }\end{array}$ \\
\hline & Conveniência & $\begin{array}{l}\text { Relacionada às vantagens qu } \\
\text { mobilidade (Redman et al., }\end{array}$ \\
\hline & Flexibilidade & $\begin{array}{l}\text { Possibilidades que o automó } \\
\text { disponiveis (Beirão \& Cabral, }\end{array}$ \\
\hline & Acessibilidade & $\begin{array}{l}\text { Facilidade proporcionada a in } \\
\text { de transporte (Geurs \& Van }\end{array}$ \\
\hline & Rapidez & Menor tempo de viagem cor \\
\hline & Confiablidade & $\begin{array}{l}\text { Facilidade com que os usuór } \\
\text { (Cardoso, 2012; LNTZ, } 200\end{array}$ \\
\hline & $\begin{array}{l}\text { Seguranca pessoal e do } \\
\text { trânsito }\end{array}$ & $\begin{array}{l}\text { Seguranca pessoal anticrimes } \\
\text { viagem (Gardner \& Abraham }\end{array}$ \\
\hline \multirow{5}{*}{$\begin{array}{l}\text { Outros } \\
\text { atributos }\end{array}$} & Custo & $\begin{array}{l}\text { Referido ao custo monetário } \\
\text { (Ortúzar \& Willumsen, } 201\end{array}$ \\
\hline & Proteção ao clima & $\begin{array}{l}\text { Proteccão proporcionada pelo } \\
\text { (De Witte et al., 2013). }\end{array}$ \\
\hline & $\begin{array}{l}\text { Consciência } \\
\text { ambiental }\end{array}$ & Relacionado a preocupaç̃oes \\
\hline & Saúde & Relacionado aos beneficicos ì \\
\hline & Capacidade de carga & Quantidade de passageiros $\theta$ \\
\hline \multicolumn{3}{|c|}{$\begin{array}{l}\text { Fonte: Elaborado pelo autor (2015) com base em: Beir̃o \& Cabral (2007), Cardoso } \\
\text { Abraham (2007), Geurs \& Van Wee (2004), LNTZ (2007), Ortúzar \& Willumsen (201 }\end{array}$} \\
\hline \multicolumn{3}{|c|}{ 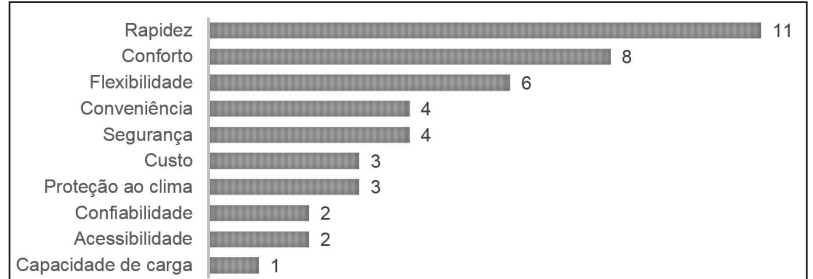 } \\
\hline
\end{tabular}

Figura 1 - Principais motivos pelos quais as pessoas escolheram o automóvel, classificados de acordo com o número de pesquisas nas quais são citados Fonte: Elaborado pelo autor (2015) com base em: Anable \& Gatersleben (2005), Bamberg \& Schmidt e Van Lange et al. (citado por Anable \& Gatersleben, 2005), Beirão \& Cabral (2007), De Witte et al. (2013), Eriksson et al. (2013), Galindo et al. (2014), Gärling \& Schuitema (2007), Hagman (2003), Bergstad et al. (2011), Steg (2005), Steg et al. (2001).

quais associam o veículo à proteção pessoal oferecida (Hagman, 2003). Entretanto, o custo é percebido como uma desvantagem por alguns, tipicamente considerando somente os gastos com combustível e/ou estacionamento, e não todos os associados à posse e operação do veículo - isso talvez devido à falta de costume e à dificuldade que representa o seu cálculo (Beirão \& Cabral, 2007; Gardner \& Abraham, 2007). Além disso, usuários de automóvel tendem a admitir que o TP é mais barato, mas não necessariamente é um fator determinante para mudar de modo (Beirão \& Cabral, 2007; De Witte et al., 2013). Das pesquisas analisadas, apenas duas (Beirão \& Cabral, 2007; Steg et al., 2001) tratavam do tema da acessibilidade como motivo para escolha do automóvel.

Hagman (2003), em estudo realizado na Suécia, concluiu que as desvantagens relacionadas à segurança do trânsito e a temas ambientais derivavam usualmente de um discurso público que as pessoas repetiam, sem terem consciência real do problema. No entanto, vantagens, como flexibilidade e rapidez, e desvantagens, como custo, tendiam a derivar de uma experiência pessoal. Logo, a experiência não somente proporciona ao usuário conhecimento a ser usado durante o processo de escolha, mas também permite criar uma base comparativa que o levará ou não a mudar de modo (De Witte et al., 2013). 
Não só a experiência de viagem influenciará a percepção dos atributos mais relevantes de um modo do que a outros, mas também diversas características da viagem e o seu propósito. Em uma pesquisa qualitativa realizada em Portugal por Beirão \& Cabral (2007), envolvendo usuários de TP e automóvel, a rapidez e a confiabilidade resultaram ser fatores-chave, especialmente em viagens com horários de chegada estabelecidos e rígidos. No caso dos usuários de automóvel, a percepção da rapidez foi maior do que na realidade, favorecendo essa modalidade em relação ao TP. Esses usuários também se sentem com maior controle da situação dentro de seus veículos, acreditando que podem buscar caminhos alternativos que possibilitem um menor tempo da viagem. Adicionalmente, os usuários de automóvel tendem a evitar a transferência a outras modalidades enquanto não perceberem que esta gerará maior rapidez. Em geral, os usuários que costumam usar o automóvel esperam ter uma experiência de viagem com conforto, o que, no caso do TP, inclui assentos disponíveis, ambiente agradável e veículos não lotados.

Embora a incidência do uso do automóvel nas cidades brasileiras tenha crescido nos últimos anos (Observatório das Metrópoles, 2013), encontraram-se poucos estudos analisando os motivos dessa escolha, especialmente no caso de megaeventos esportivos. Na segunda edição de uma pesquisa realizada no Brasil sobre a percepção da mobilidade urbana, Galindo et al. (2014) identificaram e classificaram os principais motivos de escolha dos distintos modos de transporte existentes em cidades brasileiras, considerando se a modalidade usada era a única disponível, a mais rápida, saudável, confortável, mais barata ou pela facilidade de seu uso. No caso do automóvel, os motivos mais comuns pelos quais as pessoas o escolheram foram por ser mais rápido e confortável. Tanto nessa edição como na anterior, para os usuários de automóvel, o custo não estava entre os motivos mais importantes, talvez porque normalmente é a modalidade mais custosa, diferentemente dos usuários de TP e dos modos não motorizados, que o consideraram dentre os principais motivos. Os usuários de automóvel foram também os únicos que acharam o conforto importante para a escolha.

Portanto, definir quais os principais motivos instrumentais que levam ao uso do automóvel dependerá das especificidades de cada caso. De acordo com as fontes analisadas, esses motivos parecem mais sensíveis a fatores como o propósito da viagem, modos de transporte alternativos disponíveis, número de transferências entre os modos de transporte, distâncias até o destino, disponibilidade de estacionamento, sexo, idade e a experiência. A rapidez e o conforto parecem se destacar para os usuários de automóvel. Embora a acessibilidade tenha mostrado afetar o uso desse modo, ela não costuma ser considerada como um motivo de escolha dos usuários.

Especificamente para o caso de megaeventos, não foram encontradas pesquisas relacionadas aos motivos que interferem na escolha modal dos espectadores e/ou que incentivam as viagens de automóvel. Inclusive, pesquisas relacionadas a esses temas na América Latina resultaram menos frequentes que em países norte-americanos, asiáticos e europeus. As pesquisas encontradas estavam focadas em descrever e comparar esses motivos entre modos de transporte de acordo com diversos propósitos de viagens, como trabalho, educação e lazer (Abrahamse et al., 2009; Anable \& Gatersleben, 2005; Eriksson et al., 2008; Eriksson et al., 2013; Gardner \& Abraham, 2007; Gärling et al., 2002; Gatersleben \& Appleton, 2007; Bergstad et al., 2011; Schwanen et al., 2012). Megaeventos esportivos certamente podem ser equiparados a propósitos como lazer, mas as particularidades do evento dada a sua magnitude, as medidas de restrição de uso de modos menos sustentáveis e o caráter festivo, especialmente em um país onde o futebol passa a ser mais do que um jogo, parecem sugerir que o tema deva ser tratado de outra maneira a fim de gerar estratégias e medidas efetivas. De fato os megaeventos, como já citado, devem ser aproveitados para promover novos comportamentos e mudar atitudes mais sustentáveis (Malhado \& Rothfuss, 2013; Flórez et al., 2014), mas, para isso, é preciso entender quais os motivos daqueles que escolhem o automóvel, tanto os residentes quanto os turistas.

\section{Caracterização da área de estudo, da pesquisa no Maracanã e sua amostra}

Os jogos da CC2013, realizados na cidade do Rio de Janeiro, tiveram como sede o emblemático estádio Jornalista Mário Filho, conhecido como Maracanã, localizado em uma área próxima do centro e com boa acessibilidade, servida por transporte de alta capacidade (metrô e trem), diferentes e diversificadas 
linhas de ônibus, além de condições urbanas na área adjacente que favorecem as viagens a pé. Entretanto, por não dispor de uma rede estruturante de TP que cubra o território metropolitano de forma equitativa e integrada, algumas regiões tiveram um acesso mais restrito ao estádio.

Durante os dias de jogos, a fim de promover uma melhor mobilidade aos espectadores, foram implementados pontos de bloqueio de trânsito, rotas alternativas, restrições de estacionamento, alteração dos itinerários das linhas de ônibus e operação especial dos trens (aumento da oferta durante a saída dos jogos) e metrô (passagem gratuita para os espectadores). Adicionalmente, foram incluídas linhas especiais de ônibus entre locais estratégicos com estações de metrô (Rio de Janeiro, 2013).

As restrições de acesso no entorno do Maracanã impossibilitaram a abordagem de usuários de automóvel nos locais de estacionamento, razão pela qual foram formulados dois questionários: um geral, relacionado à caracterização da viagem e ao perfil dos usuários que assistiram aos jogos da CC2013; e outro aplicado especificamente àqueles que usaram o automóvel, explorando os motivos da escolha, a avaliação da experiência, o costume de usar essa modalidade para ir até o Maracanã e no seu dia a dia, bem como se voltariam à Copa do Mundo 2014 de automóvel.

Os questionários foram aplicados no entorno do estádio do Maracanã durante três dias de jogos, dois deles em finais de semana e um em uma quinta-feira. Com base em entrevistas aleatórias, foi obtido um total de 1.568 questionários, dos quais 20\% corresponderam a usuários que utilizaram automóvel (13\% inteiramente até o estádio e $7 \%$ de forma integrada com outra modalidade, predominantemente o metrô).

Para determinar os motivos que levaram e levariam em um futuro a usar o automóvel, foram feitas perguntas abertas, posteriormente processadas e classificadas nas respectivas categorias, de acordo com a bibliografia consultada. Entretanto, na avaliação da experiência, o usuário mediu a qualidade da viagem como um todo, assim como em relação aos cinco principais benefícios associados a esse modo de transporte, citados pelos entrevistados como acessibilidade, conforto, segurança pessoal e do trânsito, rapidez e custo. Essa medição foi feita por meio de itens do tipo Likert, em uma escala de cinco pontos, variando desde muito ruim (1) até muito bom (5) para qualificar a experiência. De acordo com Boone \& Boone (2012), foram utilizadas a mediana como tendência central e a frequência para indicar a variabilidade das respostas.

Durante os jogos da CC2013, a maioria dos usuários entrevistados (60\%) dispunha de automóvel, dos quais $40 \%$ preferiram outras opções, em particular o metrô, e só $20 \%$ optaram pelo automóvel - este último grupo será a seguir sucintamente caracterizado.

No que diz respeito à idade dos usuários de automóvel, em termos relativos, observou-se na Tabela 2 que os usuários de automóvel estão proporcionalmente mais presentes entre 41 a 64 anos, faixa etária na qual a posse do veículo costuma ser maior e as condições de mobilidade por meio de outros modos são limitadas devido às características físicas e/ou à tendência de formar ou expandir o núcleo familiar (Ortúzar \& Willumsen, 2011). Já quanto ao sexo, a predominância dos homens dentre os usuários de automóvel poderia ser explicada pela natureza do evento.

Foram considerados três grupos de participantes: moradores, turistas nacionais e internacionais, entendendo-se como moradores todos aqueles com residência na Região Metropolitana do Rio de Janeiro

Tabela 2 - Porcentagem por sexo, faixa etária e local de residência, de acordo com 0 total de viagens e com as viagens de auto

\begin{tabular}{|c|c|c|}
\hline Faixa etária & $\begin{array}{c}\text { Total das } \\
\text { viagens } \\
(\%)\end{array}$ & $\begin{array}{c}\text { Viagens de } \\
\text { auto (\%) }\end{array}$ \\
\hline 18 a 25 & 24,35 & 15,63 \\
\hline 26 a 40 & 48,33 & 44,38 \\
\hline 41 a 55 & 21,10 & 30,00 \\
\hline 56 a 64 & 4,74 & 9,38 \\
\hline 65 ou mais & 1,48 & 0,63 \\
\hline \multicolumn{3}{|l|}{ Sexo } \\
\hline Masculino & 71,68 & 74,68 \\
\hline Feminino & 28,32 & 25,32 \\
\hline \multicolumn{3}{|l|}{ Local de residência } \\
\hline $\begin{array}{l}\text { Morador da Região Metropolitana } \\
\text { do Rio de Janeiro (RMRJ) }\end{array}$ & 67,71 & 65,38 \\
\hline Município Rio de Janeiro & 52,06 & 43,59 \\
\hline Outros municipios da RMRJ & 15,65 & 21,79 \\
\hline Turista nacional & 30,46 & 34,62 \\
\hline Turista internacional & 1,83 & 0,00 \\
\hline
\end{tabular}

Fonte: Elaborado pelo autor (2015) com base nos resultados dos questionários aplicados durante a Copa das Confederações 2013 (CC2013). 


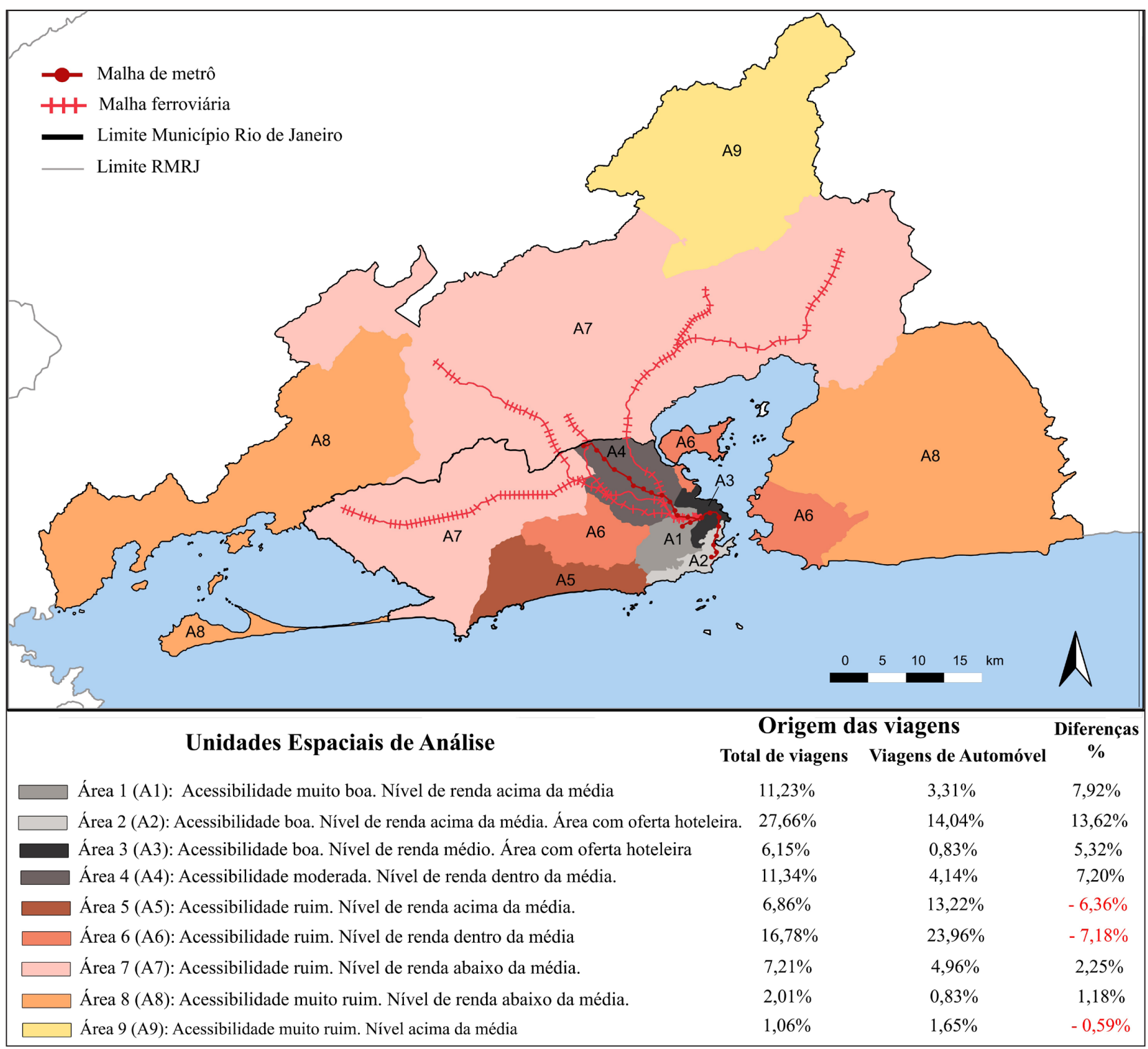

Figura 2 - Mapa da Região Metropolitana do Rio de Janeiro (RMRJ), subdividida em áreas de acordo com nível de renda e acessibilidade por meio de rede metroferroviária, com proporção de viagens totais e de automóveis de acordo com cada área Fonte: Elaborado pelo autor (2015) com base nos resultados dos questionários aplicados durante a Copa das Confederaç̃os 2013 (CC2013).

$\left(\right.$ RMRJ) $^{1}$ (Figura 2) e como turistas nacionais aqueles com residência em outras regiões do país, fora da RMRJ.

Moradores da RMRJ e turistas nacionais foram os mais propensos a usar o automóvel (Tabela 2). No caso dos turistas nacionais, a maioria dos usuários era

\footnotetext{
${ }^{1}$ Para fins desta pesquisa, incluímos à área metropolitana, constituída pelos 17 municípios enunciados no art. $1^{\circ}$ da Lei Complementar $\mathrm{n}^{\circ} 133$, de 15 de dezembro de 2009, os municípios de Petrópolis e Mangaratiba, por já terem feito parte dela (Morgado, 2005) e em função da proximidade, da interação com a região e da aparente relevância deles quanto à participação na Copa das Confederações.
}

oriunda da região Sudeste, uma das mais ricas do país, com predominante participação dos Estados do Rio de Janeiro e São Paulo, bem como de localidades que distaram até aproximadamente $400 \mathrm{~km}$ do Maracanã. Em contraste, o turista internacional foi o menos propenso a usar essa modalidade, provavelmente por não dispor do automóvel na cidade e pelo seu natural desconhecimento da rede viária e condições de acesso.

Para representar o nível de renda dos usuários, foi utilizado o número de domicílios com mais de cinco salários mínimos per capita em cada local de residência, de acordo com dados do Censo 2010 (IBGE, 
2010). Nesse sentido, observou-se que os usuários mais propensos ao uso do automóvel $(93,02 \%)$ têm um nível de renda igual ou superior à média nacional (1,31 salário mínimo per capita), segundo o IBGE (2010).

A fim de investigar a distribuição espacial dos usuários de automóvel, a Figura 2 apresenta a RMRJ dividida em nove áreas, de acordo com o nível de acessibilidade e renda. Apresenta, também, a malha metroferroviária da região e a proporção do total de viagens e das viagens de automóveis geradas pelo megaevento e originadas em cada uma das nove áreas investigadas.

A origem das viagens em $86,36 \%$ dos casos foi a mesma do local de residência dos espectadores. As restantes foram realizadas a partir de áreas com oferta hoteleira na cidade do Rio de Janeiro (áreas 2, 3 e 5 da Figura 2). Aliás, quando comparado o nível de renda com a origem das viagens, é possível observar que áreas com valor igual ou superior à média apresentaram uma participação proporcionalmente maior quanto ao uso do automóvel (áreas 5, 6 e 9 da Figura 2). Aquelas com nível de renda acima da média, mas com acessibilidade em TP muito boa ou até moderada (áreas 1 a 4), deram preferência a modos de alta capacidade, fundamentalmente ao metrô.

Devido às restrições de estacionamento impostas pelo plano operacional de transporte, 33\% dos entrevistados deixaram o automóvel em estacionamentos próximos de estações de TP e continuaram sua viagem em outra modalidade. A maioria desses usuários foi constituída por moradores da RMRJ (85\%), provavelmente porque eles conhecem melhor o sistema de transporte e os potenciais locais de integração com outros modos.

\section{Motivos da escolha modal e avaliação da experiência de usuários de automóvel}

\section{Motivos de escolha do automóvel} durante a CC2013

A fim de se conhecer os motivos que incentivaram a escolha do automóvel para ir aos jogos durante a CC2013, foram levantadas e sistematizadas as razões pelas quais as pessoas optaram por essa modalidade. Diferente da bibliografia revisada, na qual a acessibilidade se mostrou pouco valorizada, neste caso foi a razão mais frequente (29\%), apesar das restrições impostas pelo plano de mobilidade no entorno do Maracanã durante os dias de jogo (Tabela 3). Segundo os entrevistados, a facilidade de acesso até o estádio (12\%), a falta de TP de qualidade e próximo à origem da viagem (11\%) e a dificuldade para pegar TP ou táxi após o jogo (6\%) explicaram essa frequência.

A acessibilidade foi mais valorizada pelos moradores da RMRJ, especialmente aqueles com origem de viagem em áreas mais distantes e com restrições de acesso ao TP até o Maracanã, o que parece indicar que a política de restrição implementada é mais efetiva em usuários cuja origem da viagem está localizada em áreas com alternativas de acesso por meio de outras modalidades, particularmente as relativamente mais próximas ao estádio.

Entretanto, a rapidez - o segundo atributo mais relevante - foi mais valorizada pelos turistas nacionais, especialmente aqueles com origem de viagem na região Sudeste, em que o uso do automóvel se mostrou mais direto que as demais opções.

0 conforto foi um aspecto valorizado pelos usuários, independentemente da origem dispor ou não de modos alternativos de transporte ou de se encontrarem a distâncias mais próximas ou remotas ao estádio.

A conveniência foi expressa pela facilidade que proporciona o automóvel para quem não conta com TP próximo e de qualidade (11\%) e devido à dificuldade que representa ter de pegar outro modo de transporte após o jogo (6\%). Foi mais valorizada

Tabela 3 - Principais motivos pelos quais os usuários de automóvel escolheram esse modo

\begin{tabular}{cc}
\hline Motivos da escolha do automóvel & $\%$ \\
\hline Acessibilidade & 29 \\
Rapidez & 21 \\
Conforto & 19 \\
Conveniência & 17 \\
Confiabilidade & 8 \\
Segurança pessoal e no trânsito & 3 \\
Custo & 2 \\
Flexibilidade & 1 \\
Total & $\mathbf{1 0 0}$ \\
\hline
\end{tabular}

Fonte: Elaborado pelo autor (2015) com base nos resultados dos questionários aplicados durante a Copa das Confederações 2013 (CC2013). 
também por moradores da RMRJ, com origem de viagem em locais distantes e de difícil acesso por meio de outras modalidades.

A confiabilidade, medida em relação à certeza de se chegar no horário previsto ou por falta de informações disponíveis sobre as outras modalidades, foi mais valorizada pelos turistas nacionais com origem de viagem na região Sudeste do que pelos moradores da RMRJ. Naturalmente, o turista conhece menos sobre a cidade, não estando acostumado a usar o sistema de transporte, mas esse fato também sinaliza a falta de informações e divulgação sobre os modos de transporte disponíveis na cidade que um evento desse porte deveria ter.

Apesar de a segurança e flexibilidade serem motivos também valorizados na literatura (Anable \& Gatersleben, 2005; Eriksson et al., 2013; Hagman, 2003; Bergstad et al., 2011; Steg et al., 2001), não o foram nesta nossa pesquisa. 0 primeiro motivo tenha sido provavelmente pelo esquema de segurança montado no entorno do estádio e em estações de metrô, modalidade mais usada no caso daqueles que foram de automóvel integrado, além do fato de as pessoas se deslocarem até o evento normalmente em grupo, o que pode reforçar a sensação de proteção e segurança, inclusive para o sexo feminino, mais sensível a esse atributo. 0 segundo motivo foi pelas particularidades do propósito da viagem, pois as pessoas tendem a se planejar previamente para se transladar especificamente ao evento.

O custo foi outro motivo pouco relevante, o que costuma ser típico considerando os usuários de automóvel. Pode-se também atribuir ao nível de renda dos espectadores e às características do evento, para o qual já se antecipava um elevado custo de estacionamento, dadas as restrições impostas. Sob essas condições, entende-se que o custo poderia não ser um motivo significativo para interferir na escolha do automóvel.

Avaliação da experiência de viagem: atributos de qualidade e custo

Após identificar as razões pelas quais os usuários teriam escolhido o automóvel, os entrevistados avaliaram a qualidade da viagem como um todo, a sua percepção sobre atributos comumente observados na viagem por automóvel e também o custo até o momento de chegar ao estádio.

Para analisar os resultados obtidos, foram estabelecidas a média e a frequência tanto da avaliação global da qualidade da viagem quanto de cada atributo, com o objetivo de conhecer a tendência central e a variabilidade das respostas, respectivamente.

A avaliação global da qualidade da viagem teve uma mediana de 4,28 - 69,30\% avaliaram como "muito boa", 28,95\%, como "boa," e apenas 1,75\%, como "nem boa nem ruim". Quanto a avaliação dos cinco atributos (Figura 3), dois deles se destacaram mais favoravelmente: conforto e segurança pessoal e do trânsito, apesar deste último não ter sido relevante no momento da escolha do automóvel (Tabela 3).

A acessibilidade, considerando a facilidade de acesso até o bairro onde se realizava o megaevento e a disponibilidade de vagas de estacionamento, foi prejudicada pelas restrições impostas (2,89 daqueles que estacionaram no entorno do estádio em relação a 3,14 do restante). Nesse sentido, os usuários que foram de automóvel integrado com outra modalidade avaliaram melhor a acessibilidade $(61 \%$ entre "muito boa" e "boa") do que usuários que chegaram com o veículo perto do estádio (55\% entre "muito boa" e "boa"); essa diferença talvez se deva ao fato de que os primeiros estacionaram em locais regulamentados, enquanto os últimos estavam sujeitos às restrições impostas.

A rapidez, em relação ao tempo de viagem com automóvel e do local de estacionamento até o estádio, foi avaliada como positiva por $61 \%$ dos entrevistados (31\% "muito bom" e 30\% "bom"). Aqueles usuários que usaram o automóvel de forma integrada avaliaram ligeiramente melhor a rapidez (56\% entre "muito bom" e "bom") do que aqueles que foram diretamente até o estádio (47\% entre "muito bom" e "bom"), apesar de que a percepção do tempo da viagem tende a ser maior quando existem transferências entre as modalidades (Beirão \& Cabral, 2007).

Já o custo foi o pior avaliado, com média de 3,00 (36\% "nem bom nem ruim"), existindo diferenças no caso daqueles que estacionaram perto do Maracanã (45\% entre "bom" e "muito bom" em relação a 53\% do restante), os quais provavelmente sofreram um maior tempo na procura de vaga, ocasionando maiores custos operacionais, além de possíveis escolhas de locais improvisados de estacionamento, às vezes com preços não regulados, devido às restrições de acesso. 


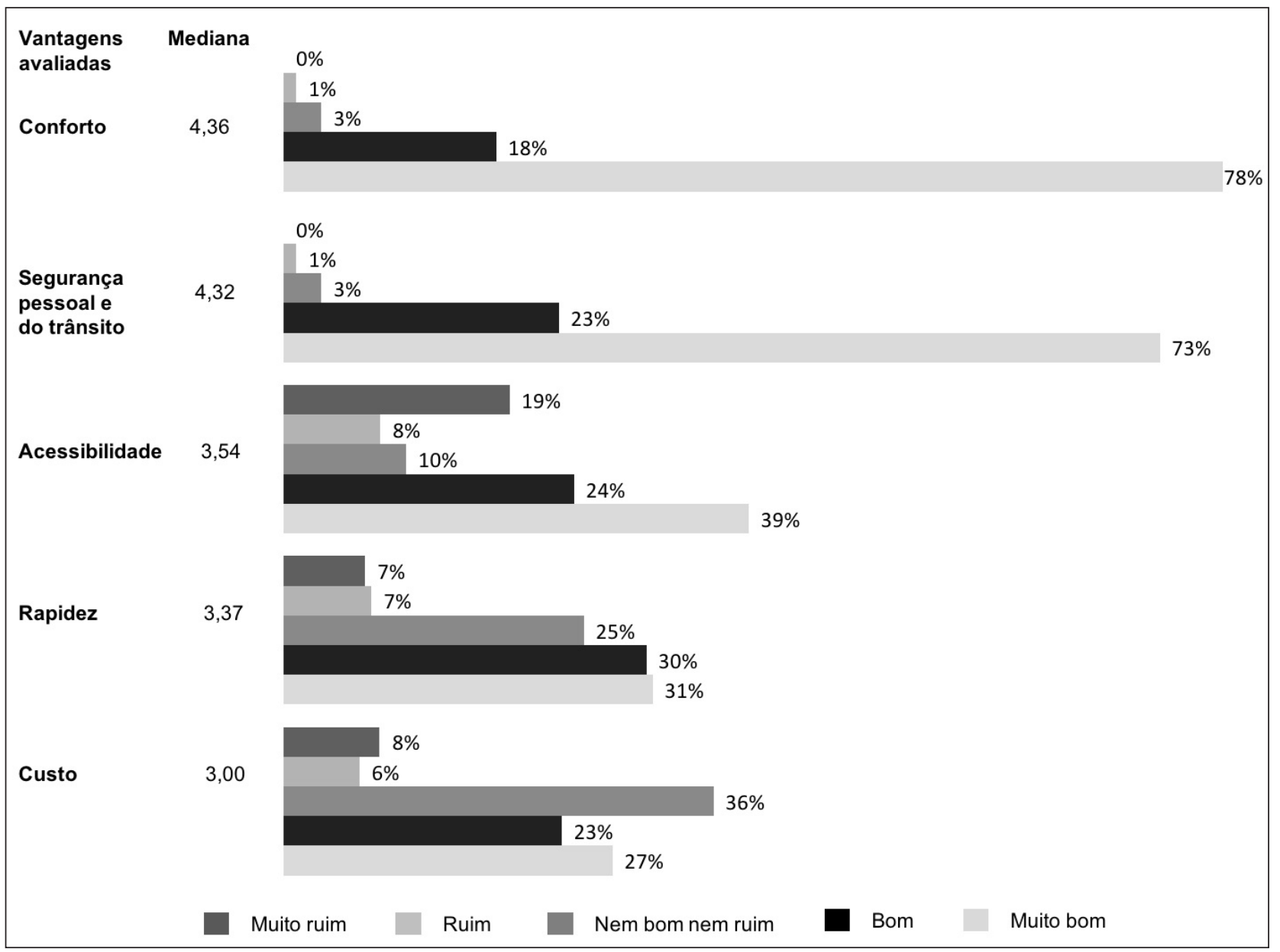

Figura 3 - Avaliação da experiência dos usuários de automóvel, valores da mediana e frequência em porcentagem Fonte: Elaborado pelo autor (2015) com base nos resultados dos questionários aplicados durante a Copa das Confederaç̃oes 2013 (CC2013).

De acordo com concepção defendida por Stradling et al. (2007), na qual os atributos mais críticos são aqueles percebidos como os mais importantes (Tabela 4) e para os quais há maior insatisfação no uso do serviço (Figura 3), os motivos mais impactados pela experiência em viajar de automóvel na CC2013 foram a rapidez e a acessibilidade, indicando que deveriam ser mais bem trabalhados e divulgados em próximos eventos, nas estratégias de conscientização e desestímulo ao uso dos automóveis.

\section{Motivos pelos quais usuários voltarão a usar automóvel em uma próxima oportunidade}

Após a experiência, quando perguntado aos usuários se eles voltariam no mesmo modo em um próximo jogo, apenas $17 \%$ deles responderam que usariam modos alternativos. Todos eles estacionaram no entorno do Maracanã e reportaram uma percepção pior da experiência de viagem (mediana de 3,83 comparada a 4,32 daqueles que não mudarão de modalidade). Quando avaliados os motivos, conforto e segurança foram mais bem avaliados (mediana de 4,41 em ambas em relação a 4,37 e 4,31, respectivamente, para aqueles menos propensos à mudança), enquanto $\mathrm{a}$ acessibilidade $(2,85$ a 3,48$)$, a rapidez $(2,84$ a 3,41$)$ e o custo $(2,49$ a 3,05$)$ receberam piores avaliações (Figura 4).

Estes usuários mais propensos à mudança também foram aqueles com experiência em usar modos alternativos cotidianamente e também para ir até o estádio, especialmente homens entre 18 a 40 anos. No caso de moradores da RMRJ, eles compreendem dois grupos: por aqueles que moram no bairro onde se localiza o estádio, cujas distâncias não superam os $2 \mathrm{~km}$, e que afirmam que irão a pé ou de metrô; e aqueles que residem em áreas distantes e periféricas, mas com 
Tabela 4 - Motivos pelos quais os usuários afirmaram que vão usar novamente 0 automóvel

\begin{tabular}{|c|c|c|c|}
\hline \multirow{2}{*}{$\begin{array}{l}\text { Motivos para escolher } \\
\text { o automóvel }\end{array}$} & \multirow{2}{*}{$\begin{array}{c}\text { \% dos que voltariam a } \\
\text { escolher o automóvel - após } \\
\text { a experiência }\end{array}$} & \multirow{2}{*}{$\begin{array}{l}\% \text { referente à escolha } \\
\text { inicial - antes da experiência }\end{array}$} & \multirow{2}{*}{$\begin{array}{c}\text { Diferença } \\
\text { (\%) }\end{array}$} \\
\hline & & & \\
\hline Conforto & 35 & 19 & 16 \\
\hline Rapidez & 17 & 21 & -4 \\
\hline Conveniência & 17 & 17 & 0 \\
\hline Acessibilidade & 14 & 29 & -15 \\
\hline Confiabilidade & 8 & 8 & 0 \\
\hline Segurança & 6 & 3 & 3 \\
\hline Custo & 3 & 2 & 1 \\
\hline Flexibilidade & 0 & 1 & -1 \\
\hline Total & 100 & 100 & - \\
\hline
\end{tabular}

Fonte: Elaborado pelo autor (2015) com base nos resultados dos questionários aplicados durante a Copa das Confederaç̃oes 2013 (CC2013).

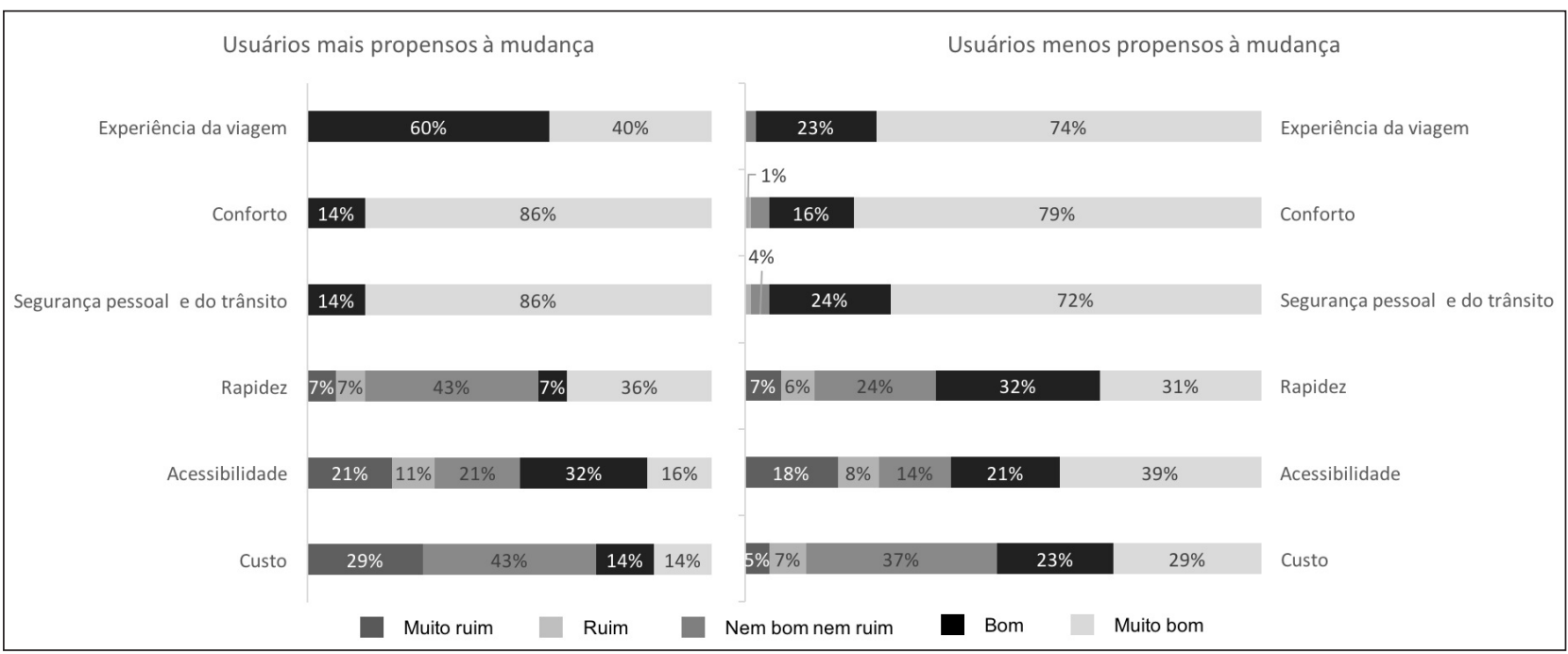

Figura 4 - Avaliação da experiência de viagem de acordo com usuários mais ou menos propensos a mudar de modalidade Fonte: Elaborado pelo autor (2015) com base nos resultados dos questionários aplicados durante a Copa das Confederaç̃ões 2013 (CC2013).

nível de renda dentro da média (área 4 da Figura 2), e que afirmam que irão usar coletivos de uso privado, TP de superfície (ônibus) ou vans, o que parece indicar que distâncias mais próximas, disponibilidade de modos alternativos e nível de renda menor tendem a ser fatores mais sensíveis à transferência modal.

Já no caso de turistas nacionais, aqueles mais dispostos a mudar são os originários de regiões brasileiras mais longínquas, hospedados em áreas hoteleiras da RMRJ bem servidas pelo metrô (área 2 da Figura 2) e que afirmaram usar essa modalidade em outra oportunidade.

Os usuários menos propensos a mudanças tendem a ser mulheres e homens de 41 anos ou mais, tanto da RMRJ como das localidades mais próximas à região. No caso da RMRJ, eles moram em áreas mais distantes com restrições de acessibilidade e com nível de renda acima da média.

As razões pelas quais os usuários utilizariam novamente o automóvel não seriam as mesmas que as sinalizadas antes da experiência, conforme mostra 
a Tabela 4, na qual constam, para cada motivo de escolha do automóvel, as percentagens antes e após a experiência, incluindo a diferença entre elas.

A acessibilidade, classificada originalmente como o principal motivo para escolher o automóvel, passou a ser a quarta razão, além de ter apresentado a maior redução percentual (15\%), provavelmente porque as restrições impostas pelo plano de mobilidade foram acima do estimado previamente pelos usuários.

Entretanto, o conforto, que foi o terceiro motivo pelo qual as pessoas tinham escolhido o automóvel, passou a ser o mais valorizado, tendo apresentado o maior aumento percentual (16\%). De fato, na avaliação da experiência, foi o atributo mais bem avaliado, inclusive por aqueles que afirmam usar, no seu dia a dia ou para ir até o estádio, outras modalidades mais sustentáveis. Isso pode indicar não só que os usuários são mais sensíveis a esse atributo que a outros, mas também que o sistema de TP atual não satisfaz às necessidades de conforto dos usuários.

Após a experiência, a rapidez segue sendo o segundo motivo mais valorizado pelos usuários que pensam em retornar de automóvel, apesar de menos usuários concordarem com a importância dela na escolha, apresentando uma redução de 4\% (Tabela 4).

Outros motivos se mantiveram iguais em termos de valoração e posição após a experiência (conveniência e confiabilidade) ou se mantiveram no mesmo lugar, mas incrementaram suas porcentagens (segurança e custo).

Em geral, a experiência de viagem no dia do evento parece modificar os motivos de escolha do automóvel, mas não necessariamente é efetiva o suficiente para provocar mudanças para modos mais sustentáveis, o que explicita a importância das condições de estacionamento para os usuários de automóvel no processo decisório.

Já a experiência dos usuários em modos de transporte mais sustentáveis no dia a dia ou para ir ao estádio parece ser um fator mais determinante para mudança, desde que a distâncias caminháveis ou que outros modos mais sustentáveis, como o TP, sejam acessíveis, o que realça o papel da acessibilidade.

Apesar dos principais motivos valorizados pelos usuários de automóvel, Galindo et al. (2014) registraram que os brasileiros parecem valorizar mais o automóvel pelo conforto e rapidez, enquanto o custo resulta pouco relevante, provavelmente pelas características socioeconômicas dos espectadores do megaevento, além dos custos operacionais de uso do veículo.

0 conforto, no entanto, deveria ser um atributo mais explorado nas modalidades alternativas para determinar e satisfazer as preferências dos usuários do automóvel e desestimular seu uso.

\section{Conclusões}

Entender os fatores e os motivos que influenciam a escolha do automóvel é importante a fim de se ter um melhor conhecimento de quando e por que as pessoas preferem essa modalidade do que a outra, tornando-se fundamental para se formular políticas mais efetivas de redução de uso desse modo de transporte.

No caso específico do Brasil, para alguns daqueles que dispõem de automóvel e contam com maior nível de renda, a falta de investimentos na área de infraestrutura de TP tem sido superada com a posse e um uso mais intensivo do automóvel (Andrade \& Portugal, 2012; Rio de Janeiro, 2005). De acordo com o Observatório das Metrópoles (2013), a frota de automóveis no Brasil aumentou 104,5\% nos últimos dez anos.

Os resultados parecem sinalizar que o plano de mobilidade para a CC2013 de alguma forma funcionou, mas poderia ter tido um melhor desempenho se fosse baseado em estudos mais elaborados, que considerassem as especificidades do contexto que envolve um megaevento esportivo e as necessidades, gostos e preferências dos usuários, os quais, no final, determinaram a escolha modal. Porém o número de usuários que foram de automóvel (20\%) foi muito acima do valor estabelecido no plano de mobilidade, cuja previsão era de que o automóvel não seria usado. Inclusive, esse percentual esteve acima dos $16 \%$ que usam o transporte individual em relação ao total das viagens realizadas cotidianamente na RMRJ (Rio de Janeiro, 2005).

0 plano contemplou polos geradores de viagens, como aeroportos, hotéis e rodoviárias, mas não a possibilidade de locais que atualmente funcionam na cidade como terminais de transferência do automóvel para modos mais sustentáveis. Esse comportamento já representa um segmento da população mais consciente das desvantagens do uso do automóvel para esse caso específico e que simplesmente faz uso dele pelas restrições de acessibilidade no local 
de origem da viagem, o que manifesta novamente a necessidade de investimento nessas áreas.

A experiência da viagem não resultou ser um fator determinante na mudança modal, mas sim a experiência em modalidades mais sustentáveis. Por isso seria importante aprimorar a qualidade do TP da cidade conforme as necessidades dos usuários, promovendo o seu uso. A falta de modos alternativos de transporte disponíveis na origem das viagens e as distâncias a serem percorridas foram também determinantes na escolha do automóvel, o que deve ser corrigido nos planos de mobilidade, reforçando e divulgando medidas de restrição ao uso do automóvel ou mesmo possibilidades de integração ao TP.

Mesmo que os motivos sejam suscetíveis a mudar no tempo e que a hierarquização destes dependa de cada contexto específico, o que é quase impossível generalizar (Redman et al., 2013), parece que, no caso da RMRJ, os sistemas de transporte alternativos ao automóvel apresentam uma forte deficiência quanto a atributos como o conforto. Isso ressalta a necessidade de não só restringir o acesso do transporte individual, mas de se investir na melhoria do TP e do não motorizado, tornando-os opções mais atraentes para os usuários de automóvel realizarem a transferência modal.

\section{Agradecimentos}

Ao apoio do CNPq, da Rede Ibero-Americana de Estudo em Polos Geradores de Viagens e da Universidad Simón Bolivar.

\section{Referências}

Abrahamse, W., Steg, L., Gifford, R., \& Vlek, C. (2009). Factors influencing car use for commuting and the intention to reduce it: A question of self-interest or morality? Transportation Research Part F: Traffic Psychology and Behaviour, 12(4), 317-324. http://dx.doi.org/10.1016/j.trf.2009.04.004.

Anable, J. (2005). 'Complacent Car Addicts' or 'Aspiring Environmentalists'? Identifying travel behaviour segments using attitude theory. Transport Policy, 12(1), 65-78. http:// dx.doi.org/10.1016/j.tranpol.2004.11.004.

Anable, J., \& Gatersleben, B. (2005). All work and no play? The role of instrumental and affective factors in work and leisure journeys by different travel modes. Transportation
Research Part A, Policy and Practice, 39(2-3), 163-181. http://dx.doi.org/10.1016/j.tra.2004.09.008.

Andrade, E. P., \& Portugal, L. S. (2012). Geração de viagens. In L. S. Portugal (Org.), Polos geradores de viagens orientados à qualidade de vida e ambiental: modelos e taxas de geração de viagens (p. 105-133). Rio de Janeiro: Interciência.

Beirão, G., \& Cabral, S. J. (2007). Understanding attitudes towards public transport and private car: A qualitative study. Transport Policy, 14(6), 478-489. http://dx.doi. org/10.1016/j.tranpol.2007.04.009.

Bergstad, C. J., Gamble, A., Hagman, O., Polk, M., Gärling, T., \& Olsson, L. E. (2011). Affective-symbolic and instrumentalindependence psychological motives mediating effects of socio-demographic variables on daily car use. Journal of Transport Geography, 19(1), 33-38. http://dx.doi. org/10.1016/j.jtrangeo.2009.11.006.

Boone, H. N. Jr., \& Boone, D. A. (2012). Analyzing Likert Data. Journal of Extension, 50(12)

Cardoso, B. C. (2012). Um procedimento para a transferência modal do usuário do ônibus para o trem. Rio de Janeiro: Programa de Engenharia de Transportes - COPPE/UFRJ.

De Witte, A., Hollevoet, J., Dobruszkes, F., Hubert, M., \& Macharis, C. (2013). Linking modal choice to motility: a comprehensive review. Transport Research Part A, 49, 329-341.

Eriksson, L., Friman, M., \& Gärling, T. (2013). Perceived attributes of bus and car mediating satisfaction with the work commute. Transportation Research Part A, Policy and Practice, 47, 87-96. http://dx.doi.org/10.1016/j. tra.2012.10.028.

Eriksson, L., Garvill, J., \& Nordlund, A. M. (2008). Interrupting habitual car use: The importance of car habit strength and moral motivation for personal car use reduction. Transportation Research Part F: Traffic Psychology and Behaviour, 11(1), 10-23. http://dx.doi.org/10.1016/j. trf.2007.05.004.

Flórez, J., Muniz, J., \& Portugal, L. (2014). Pedestrian quality of service: lessons from Maracanã stadium. Procedia: Social and Behavioral Sciences, 160, 130-139. http://dx.doi. org/10.1016/j.sbspro.2014.12.124.

Galindo, E. P., Lima, V. C., \& Magalhães, M. T. (2014). Percepção sobre a mobilidade urbana no Brasil: uma análise dos dados do Sistema de Indicadores de Percepção Social. In 
XXVIII Congresso de Pesquisa e Ensino em Transportes (p. 1-12). Curitiba: ANTP.

Gardner, B., \& Abraham, C. (2007). Psychological correlates of car use: a meta-analysis. Transportation Research Part F: Traffic Psychology and Behaviour, 11(4), 300-311. http:// dx.doi.org/10.1016/j.trf.2008.01.004.

Gärling, T., \& Schuitema, G. (2007). Travel demand management targeting reduced private car use: effectiveness, public acceptability and political feasibility. The Journal of Social Issues, 63(1), 139-153. http://dx.doi. org/10.1111/j.1540-4560.2007.00500.x.

Gärling, T., Eek, D., Loukopoulosa, P., Fujiic, S., JohanssonStenmand, O., Kitamurac, R., Pendyalae, R., \& Vilhelmsonf, B. (2002). A conceptual analysis of the impact of travel demand management on private car use. Transport Policy, 9(1), 5970. http://dx.doi.org/10.1016/S0967-070X(01)00035-X.

Gatersleben, B. (2007). Affective and symbolic aspects of car use: a review. In: T. Gärling, \& L. Steg (Eds.), Threats to the quality of urban life from car traffic: problems causes and solutions (p. 219-234). Amsterdam: Elsevier.

Gatersleben, B., \& Appleton, K. M. (2007). Contemplating cycling to work: Attitudes and perceptions in different stages of change. Transportation Research Part A, Policy and Practice, 41(4), 302-312. http://dx.doi.org/10.1016/j. tra.2006.09.002.

Geurs, K. T., \& Van Wee, B. (2004). Accessibility evaluation of lands-use and transport strategies: review and research directions. Journal of Transport Geography, 12(2), 127-140. http://dx.doi.org/10.1016/j.jtrangeo.2003.10.005.

Hagman, O. (2003). Mobilizing meanings of mobility: car users' constructions of the goods and bads of car use. Transportation Research Part D, Transport and Environment, 8(1),1-9.http://dx.doi.org/10.1016/S1361-9209(02)00014-7.

Haustein, S., Klockner, C. A., \& Blobaum, A. (2009). Car use of young adults: the role of travel socialization. Transportation Research Part F: Traffic Psychology and Behaviour, 12(2), 168-178. http://dx.doi.org/10.1016/j.trf.2008.10.003.

Instituto Brasileiro de Geografia e Estatística - IBGE. (2010). Censo 2010. Rio de Janeiro. Recuperado em 2 de maio de 2014, de http://censo2010.ibge.gov.br/en/

Land Transport New Zealand - LNTZ. (2007). Pedestrian planning and design guide. Nova Zelândia: Wellington.

Lavery, T. A., Páez, A., \& Kanaroglou, P. S. (2013). Driving out of choices: an investigation of transport modality in a university sample. Transportation Research Part A: Policy and Practice, 57, 37-46.

Malhado, A. (2012). Transporting mega-events to sustainability: assessing behavior and attitudes of tourist and residents to promote sustainable mobility for 2014 Fifa World Cup. Tübingen: Universidade de Tübingen.

Malhado, A., \& Rothfuss, R. (2013). Transporting 2014 FIFA Words Cup to sustainability: exploring residents' and tourists' atitudes and behaviuors. Journal of Policy Researh in Tourism, Leisure and Events, 5(3), 252-269. http:// dx.doi.org/10.1080/19407963.2013.801159.

Morgado, A.V. (2005). Contribuição metodológica ao estudo de localização de terminais rodoviários regionais coletivos de carga (Tese de doutorado). Programa de Pós-graduação em Engenharia de Transportes, Universidade Federal do Rio de Janeiro, Rio de Janeiro.

Observatório das Metrópoles. (2013). Evolução da frota de automóveis e motos no Brasil 2011-2012. Rio de Janeiro. Recuperado em 2 de maio de 2014, de http://www. observatoriodasmetropoles.net/download/auto_motos2013.pdf

Organisation for Economic Co-operation and Development OECD. (2011). Greening household behaviour the role of public policy. Paris: OECD Publishing. Recuperado em 5 novembro de 2013, de http://www.oecd-ilibrary.org/environment/ greening-household-behaviour_9789264096875-en

Ortúzar, J., \& Willumsen, L. (2011). Modeling transport (4th ed., p. 208-209). West Sussex: John Wiley and Sons.

Portugal, L., Flórez, J., \& Silva, A. N. (2010). Rede de pesquisa em transportes: um instrumento de transformação e melhora de vida. Transportes, 13(1), 6-16.

Ramis, J. E., \& Santos, E. A. (2012). Uso de automóveis e o caos urbano - considerações sobre o planejamento de transportes das grandes cidades. Journal of Transport Literature, 6(4), 164-177. http://dx.doi.org/10.1590/ S2238-10312012000400009.

Redman, L., Friman, M., Gärling, T. E., \& Harting, T. (2013). Quality attributes of public transport that attract car users: a research review. Transport Policy, 25, 119-127. http:// dx.doi.org/10.1016/j.tranpol.2012.11.005.

Rio de Janeiro. Governo do Estado. Secretaria de Estado de Transporte - SETRANS. (2005). Plano Diretor de Transporte Urbano. Rio de Janeiro. Recuperado em 2 de abril, 2014, de http://www.slideshare.net/Lac2009/ estudo-de-demanda-pdtu-2003 
Rio de Janeiro. Prefeitura. (2013). Prefeitura monta operação especial para a Copa das Confederações. Rio de Janeiro. Recuperado em 20 de setembro de 2013, de http://www. rio.rj.gov.br/web/smtr/exibeconteudo?id=4180882

Robbins, D., Dickinson, J., \& Calver, S. (2007). Planning transport for special events: a conceptual framework and future agenda for research. International Journal of Tourism Research, 9(5), 303-314. http://dx.doi.org/10.1002/jtr.639.

Rodrigues, J. P., Comtois, C., \& Slack, B. (2013). The geography of transport systems (3th ed.). New York: Routledge.

Ross, W. (2000). Mobility \& accessibility: the yin \& yang of planning. World Transport Policy and Practice, 6(2), 13-19.

Schwanen, T., \& Lucas, K. (2011). Understanding auto motive. In K. Lucas, E. Blummenberg, \& R. Weinberger. (Eds.), Auto motives: understanding car use behavior (p. 3-38). Bingley: Emeral Group.

Schwanen, T., Banister, D., \& Anable, J. (2012). Rethinking habits and their role in behaviour change: the case of low-carbon mobility. Journal of Transport Geography, 24, 522-532. http://dx.doi.org/10.1016/j.jtrangeo.2012.06.003.

Steg, L. (2005). Car use: lust and must. Instrumental, symbolic and affective motives for car use. Transportation Research Part A, Policy and Practice, 39(2-3), 147-162. http://dx.doi.org/10.1016/j.tra.2004.07.001.

Steg, L., \& Vlek, C. (2009). Encouraging pro-environmental behaviour: An integrative review and research agenda. Journal of Environmental Policy, 29, 309-317.
Steg, L., Vlek, C., \& Slotegraaf, G. (2001). Instrumentalreasoned and symbolic-affective motives for using a motor car. Transportation Research Part F: Traffic Psychology and Behaviour, 4(3), 151-169. http://dx.doi.org/10.1016/ S1369-8478(01)00020-1.

Stradling, S. G., Anable, J., \& Carreno, M. (2007). Performance, importance and user disgruntlement: a six-step method for measuring satisfaction with travel modes. Transportation Research Part A, Policy and Practice, 41(1), 98-106. http:// dx.doi.org/10.1016/j.tra.2006.05.013.

Tyrinopoulos, Y., \& Antoniou, C. (2012). Factors affecting modal choice in urban mobility. European Transport Research Review, 5(1), 27-39. http://dx.doi.org/10.1007/ s12544-012-0088-3.

Verplanken, B., Aarts, H., \& Van Knippenberg, A. (1997). Habit, information acquisition, and the process of making travel mode choices. European Journal of Social Psychology, 27(5), 539-560. http://dx.doi.org/10.1002/(SICI)10990992(199709/10)27:5<539::AID-EJSP831>3.0.CO;2-A.

Verplanken, B., Aarts, H., Knippenberg, A., \& Knippenberg, C. (1994). Attitude versus general habit: antecedents of travel mode choice. Journal of Applied Social Psychology, 24(4), 285-300. http://dx.doi.org/10.1111/j.1559-1816.1994. tb00583.x.

Recebido: Set. 02, 2015

Aprovado: Abr. 07, 2016 